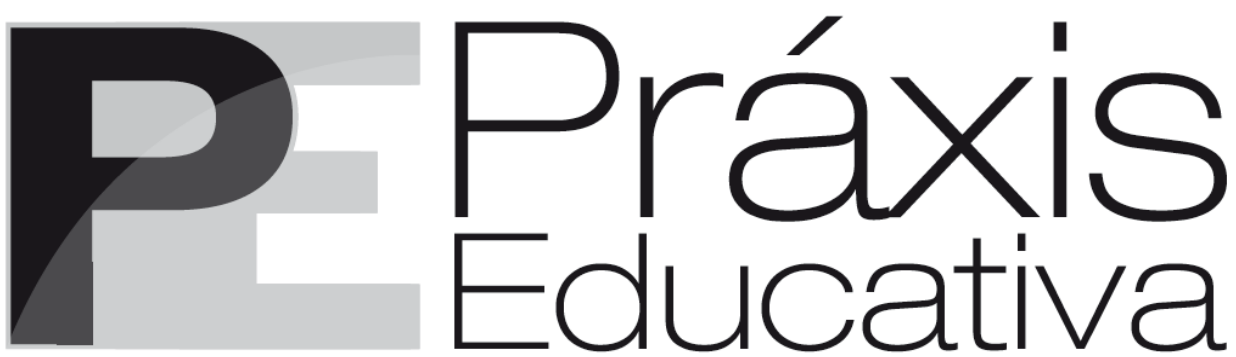

ISSN 1809-4309 (Versão online) DOI: 10.5212/PraxEduc.v.11i3.0018

\title{
BALL, Stephen J. Educação Global S. A.: novas redes de políticas e o imaginário neoliberal. Tradução de Janete Bridon. Ponta Grossa: UEPG, 2014. $270 \mathrm{p}$.
}

\section{GLOBALIZAÇÃO, REDES POLÍTICAS E NEOLIBERALISMO: AS CONTRIBUIÇÕES DE STEPHEN BALL PARA PENSAR SOBRE POLÍTICAS EDUCACIONAIS NA ATUALIDADE}

\author{
Viviane Grimm* \\ Fernando Cesar Sossai* \\ Marília Segabinazzi ${ }^{* * *}$
}

"Neoliberalismo", "redes políticas", "globalização", "educação como um grande negócio", "amigos com dinheiro"... Há tempos, muitos de nós estamos familiarizados com a circulação desses termos no meio educacional. Pelo menos durante os últimos 30 anos, muitos deles vêm sendo empregados em diversificadas análises, sobretudo por pesquisadores que tentam explicar certos fenômenos que estão impactando tanto o pensar quanto o praticar a Educação no Brasil. Seguramente, alguns devem lembrar que tais terminologias são velhas conhecidas do vocabulário neomarxista, sendo frequentemente empregadas em artigos, livros, teses e dissertações produzidas em diferentes campos de conhecimento.

Seja como for, há muito tempo temos assistido aos estudos educacionais lançarem mão de problematizações que questionam três estruturas caras à vida contemporânea: o neoliberalismo, o Estado e a globalização. Há numerosos casos de reflexões mais ou menos aprofundadas acerca das interconexões globais que impactam a Educação, sobre como os Estados nacionais vêm sendo desafiados diante de uma agenda político-econômica "mundializante" e em relação ao avanço do neoliberalismo em nosso cotidiano por meio de práticas de consumo.

Além disso, analisar a articulação entre neoliberalismo, Estado e globalização também tem sido a maneira pela qual alguns estudos educacionais têm interrogado o nosso próprio presente, perquirindo sua aceleração, suas formas de expressão demasiadamente presentistas (o

\footnotetext{
* Professora do Instituto Federal de Santa Catarina (IFSC). Doutoranda em Educação (UDESC). E-mail: $<$ vivi.grimm@gmail.com>.

** Professor da Univille. Doutorando em Educação (UDESC). E-mail: < fernandosossai@gmail.com>.

*** Doutoranda em Educação (UDESC). E-mail: <mssegabinazzi@gmail.com>.
} 
fato de enxergar quase sempre pouca coisa além dele mesmo) e a impotência de educadores e pesquisadores diante da intensificação de um conjunto de políticas neoliberais.

O que isso tudo possui de relação com "Educação Global S. A.: novas redes de políticas e o imaginário neoliberal" (Figura 1), o mais recente livro traduzido ao português do sociólogo inglês Stephen Ball ${ }^{1}$ ? Absolutamente tudo! Sem dúvida, o Livro é uma contribuição ímpar para todos os pesquisadores que se interessam pelos recentes estudos da Sociologia da Educação inglesa.

Figura 1 - Imagem da capa de Stephen J. Ball (2014)

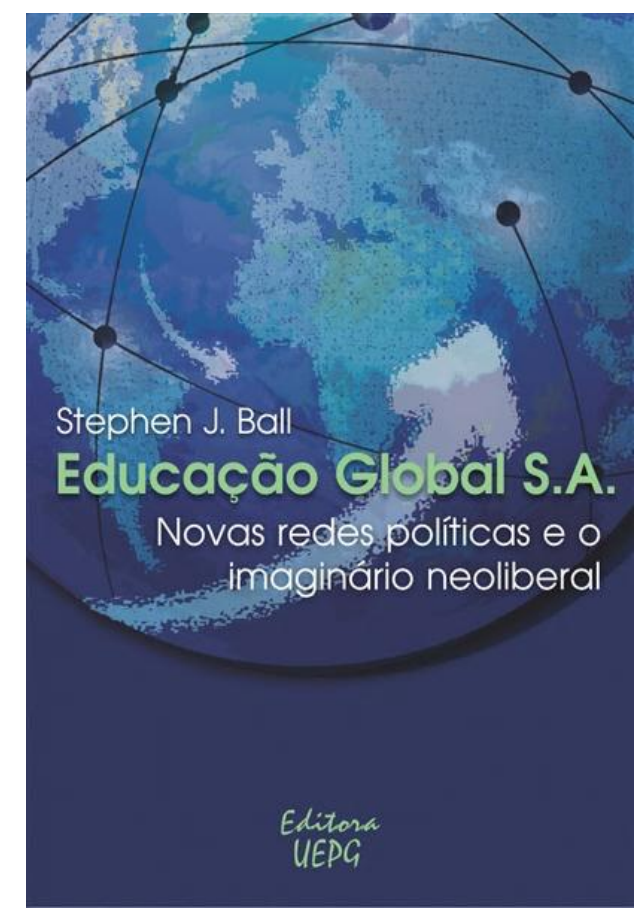

Fonte: Acervo dos autores, 2015.

Pontualmente, a publicação encontra-se organizada em sete capítulos: 1. Redes, neoliberalismo e mobilidade de políticas; 2. Fazendo neoliberalismo - mercados, Estados e amigos com dinheiro; 3 . Redes transnacionais de influência e empreendedorismo de políticas: Indiana Jones, negócios e escolaridade dos pobres; 4. "Nova" filantropia, capitalismo social e política educacional; 5. Políticas como lucro: vendendo e exportando políticas; 6. Educação como um grande negócio; 7. Dinheiro, significado e conexões de políticas.

Revisitando termos caros à Sociologia dos anos de 1980 e de 1990 (Estado, capitalismo, neoliberalismo, dinheiro, redes políticas e globalização), Ball (2014) faz um esforço intelectual no sentido de mostrar como funciona por dentro as intricadas lógicas de uma política global de educação que tem fortemente impactado países como o Brasil, mais precisamente para

\footnotetext{
1 Até 2015, Stephen J. Ball ocupou a cátedra de Karl Mannheim Professor of Sociology of Education junto ao Institute of Education - UCL (Londres). A partir de setembro de 2015, tornou-se Distinguished Service Professor of Sociology of Education. É editor do Journal of Education Policy e um dos diretores do Centre for Critical Education Policy Studies (UCL/Institute of Education). É membro da British Academy for the Humanities and Social Science (MAINARDES, 2015). Tem publicado sobre política educacional, sendo considerado um dos mais influentes pesquisadores dessa área na atualidade. Sua obra oferece um conjunto de recursos teóricos, analíticos e metodológicos, centrando-se em temáticas como: reformas educacionais, performatividade, gerencialismo, redes políticas, mercado educacional, micropolíticas e educação, entre outras.
}

Práxis Educativa, Ponta Grossa, p. 850-854, v. 11, n. 3, set./dez. 2016 Disponível em: <http://www.revistas2.uepg.br/index.php/praxiseducativa> 
BALL, Stephen J. Educação Global S. A.: novas redes de políticas e o imaginário neoliberal...

demonstrar como certos mercados globais de educação se configuraram e, hoje, estão convertidos em um negócio de escala planetária nunca antes visto.

Avançando o debate para além da certeza de que o mundo está "globalizado" e de que os Estados nacionais são vítimas do "neoliberalismo", Ball (2014) pontua diferentes projetos/programas educacionais que, ainda que imbuídos das mais nobres intenções, evidenciam como um paradigma gerencialista tem avançado em nossas sociedades e se incrustado no pensamento educacional de tal modo que parece ser a salvação da qualidade de ensino oferecido nas escolas públicas. Emblemático disso são as reflexões que o autor apresenta sobre o "Todos pela Educação", do Brasil, e outros movimentos filantrópicos similares que supostamente representam a melhoria do mundo por parte de um conjunto de instituições vinculadas à sociedade civil organizada.

Nessa mesma direção, o autor alerta sobre as limitações de alguns estudos em política educacional que se centram em uma perspectiva presa às fronteiras de um Estado-Nação e a um paradigma de política-como-governo (clássicas ideias da Modernidade). Questionando tais pontos, pormenorizadamente, o autor apresenta elementos teóricos e empíricos no âmbito de uma "sociologia cosmopolita", cuja análise considera tanto os fluxos globais de políticas de educação, quanto as complexas dinâmicas que o neoliberalismo tem assumido na contemporaneidade que vivemos e que vai muito além dos aspectos econômicos, espraiando-se por quase todas as arenas da vida social.

O neoliberalismo, de acordo com Ball (2014), é um termo vago e que precisa ser contextualizado quando empregado. Em sua concepção, trata-se de um conjunto complexo de práticas organizadas em torno de um "mercado" com penetração em quase todos os aspectos de nossas vidas, ou seja, vai muito além de uma doutrina econômica ou de um conjunto de projeto políticos. Partindo de uma abordagem pluralista, o autor considera que o neoliberalismo abrange "[...] tanto as relações materiais quanto as sociais envolvidas, que são, ao mesmo tempo, o foco neomarxista sobre a 'economização' da vida social e da 'criação' de novas oportunidades de lucro" (BALL, 2014, p. 25, grifos do autor), bem como, em uma perspectiva foucaultiana de governamentabilidade, envolve o "[...] governo das populações por meio da produção de seres empreendedores 'dispostos', 'auto-governamentáveis"' (BALL, 2014, p. 26, grifos do autor). Isto é, segundo o autor, o neoliberalismo assume diferentes dimensões da sociedade: econômica, cultural e política.

[...] o neoliberalismo está "aqui dentro" bem como "lá fora". Ou seja, o neoliberalismo é econômico (um rearranjo das relações entre o capital e o Estado), cultural (novos valores, sensibilidades e relacionamentos) e político (uma forma de governar, novas subjetividades). [...] em um sentido paradoxal, o neoliberalismo trabalha a favor e contra o Estado de maneiras mutuamente constitutivas. Ele destrói algumas possibilidades para formas mais antigas de governar e cria novas possibilidades para novas formas de governar. (BALL, 2014, p. 229, grifos do autor).

Deste modo, o neoliberalismo está estimulando a produção de "[...] novos tipos de atores sociais, sujeitos sociais híbridos que são espacialmente móveis, eticamente maleáveis e capazes de falar as linguagens do público, do valor privado e filantrópico" (BALL, 2014, p. 230), bem como está atuando de modo global a partir de "redes políticas transnacionais". Nesse contexto, as políticas educacionais estão sendo feitas "[...] em novas localidades, em diferentes parâmetros, por novos atores e organizações", requerendo dos investigadores "[...] novos métodos e conceitos e novas sensibilidades de pesquisa", superando o "territorialismo metodológico" (BALL, 2014, p. 27). 
O conceito de redes políticas ganha destaque como instrumento conceitual e analítico para o desvelamento das relações de poder em torno das disputas econômicas no campo educacional. Para o autor, as redes políticas constituem:

[...] uma nova forma de governança, embora não de uma forma única e coerente, e colocam em jogo, no processo de políticas, novas fontes de autoridade [...] as fronteiras entre o Estado, a economia e a sociedade civil estão ficando turvas; há novas vozes nas conversas sobre as políticas e novos canais por meio dos quais os discursos sobre as políticas introduzem o pensamento sobre políticas [...]. (BALL, 2014, p. 34).

Partindo desses marcadores teóricos (principalmente, neoliberalismo e redes políticas), o autor observa que muitas políticas educacionais têm sido objeto de disputa em redes políticas globais, que possuem uma gama diversificada de participantes e que envolvem não somente os governos e outros agentes nacionais, mas também organismos de atuação transnacionais (Banco Mundial, OCDE, etc.), ONGs, think tanks (pesquisadores-consultores individualmente e/ou associados a empresas de prestação de serviços educacionais), grupos de interesses oportunistas (entidades empresariais, associações religiosas, etc.), empresas internacionais de venda de "pacotes prontos" de educação, entre outros, cujos discursos ganham adesão por jogarem com a crença social de que o conhecimento é moeda de presente e de futuro de qualquer sociedade qualificada e competitiva. Ball (2014) enfatiza que:

[...] novas redes e comunidades de políticas estão sendo estabelecidas conforme os discursos neoliberais e o conhecimento fluem e ganham legitimidade e credibilidade. Estes são os novos agenciamentos de políticas com uma gama de participantes novos e velhos existentes em um novo tipo de espaço de políticas em algum lugar entre agências multilaterais, governos nacionais e negócios internacionais, dentro e além dos locais tradicionais e de circulação e formulação de políticas. (BALL, 2014, p. 220).

Nesse quadro de interesses, disputas e concorrências, as políticas educacionais apresentam-se como uma oportunidade de lucro para o "edu-business" global, tanto no sentido de venda como de doação ou filantropia em diferentes contextos (BALL, 2014). Ou seja, as próprias políticas educacionais tornam-se uma mercadoria, um negócio, um objeto de venda, de exportação ou importação, comercializado por empresas nacionais e multinacionais, podendo ser compradas, consumidas e/ou incorporadas como políticas de educação próprias de cada Estado Nacional, destacadamente pelos países mais pobres do globo. No entendimento de Ball,

[...] na interface entre a política educacional e o neoliberalismo, o dinheiro está em toda a parte. Como indiquei, a própria política é agora comprada e vendida, é mercadoria e oportunidade de lucro, há um mercado global crescente de ideias de políticas. O trabalho com políticas está também cada vez mais sendo terceirizado para organizações com fins lucrativos, que trazem suas habilidades, seus discursos e suas sensibilidades para o campo da política, por uma taxa honorária ou por um contrato com o Estado. (BALL, 2014, p. 222).

Um outro argumento que tem ganhado destaque é o discurso de "crise política do Estado", do "público", e, por extensão, da "educação pública", que tem contribuído para que o mercado se aproveite "[...] dos medos e dos desejos do público", fazendo uso de um "[...] discurso salvador que promete salvar escolas, líderes, professores e alunos do fracasso, dos terrores da incerteza e das confusões das políticas e deles mesmos - suas próprias fraquezas" (BALL, 2014, p. 160).

Opondo-se à crise do público, o privado é significado como "modelo de gestão", como o "exemplo de excelência e eficiência", considerado como a única forma de solucionar os problemas da educação pública, por meio de diferentes produtos, desde pacotes que podem ser comercializados, incluindo políticas educacionais de diferentes tipos (alfabetização, gestão, 
BALL, Stephen J. Educação Global S. A.: novas redes de políticas e o imaginário neoliberal...

tecnologias, formação de professores etc.), até soluções sob a forma de programas, de modelos de gestão, de equipamentos informáticos (softwares tablets, computadores), de materiais didáticos (apostilas, kits de livros), de assessorias, de consultorias, de treinamentos, de uma grande variedade de serviços técnicos, pedagógicos e administrativos/gerenciais que apoiam a educação na sua retaguarda. Enfim, de toda sorte de empacotamento de bens educacionais habilitados à comercialização planetária.

Nesse fazer, as empresas privadas têm percebido nos mercados de serviços educativos uma excelente oportunidade de investimento, isto é, um terreno de possibilidades políticas criadas no marco de uma estrutura política global e multilateral, que privilegia direta e indiretamente as soluções privadas para problemas públicos. A privatização do setor público, que vem ocorrendo por meio do trabalho do edu-bussiness, não é feita "[...] retirando os serviços do controle do setor público, mas sim por meio da venda de 'soluções' políticas e vias de colaboração de vários tipos com o setor público, embora algumas sejam mais significativamente colaborativas do que outras" (BALL, 2014, p. 162, grifo do autor). Os representantes do setor privado têm operado cada vez mais por dentro do próprio governo, fazendo parte e disputando suas premissas no contexto de desenvolvimento das políticas educacionais, bem como atuando in loco, por meio da doação e da venda de produtos educacionais.

Por diferentes caminhos, a obra Educação Global S.A.: novas redes de políticas e o imaginário neoliberal, além de trazer contribuições significativas para o desenvolvimento da pesquisa em políticas educacionais, problematiza o próprio campo de investigação, as limitações dos conceitos que vêm sendo empregados e as metodologias utilizadas pelos seus estudiosos. $\mathrm{Na}$ defesa de um contexto de "política educacional global", o autor recomenda que é preciso avançar em direção a investigações que analisem redes políticas e de métodos etnográficos, na tentativa de conectar iniciativas locais e globais, perscrutando "[...] as mediações locais e traduções do movimento de tecnologia da educação global” (BALL, 2014, p. 19). Afinal, conforme revelam suas pesquisas:

\footnotetext{
[...] em diferentes graus, em diferentes países, o setor privado ocupa agora uma gama de funções e de relações dentro do Estado e na educação pública em particular, como patrocinadores e benfeitores, assim como trabalham como contratantes, consultores, conselheiros, pesquisadores, fornecedores de serviços e assim por diante; tanto patrocinando inovações (por ação filantrópica) quanto vendendo soluções e serviços de políticas para o Estado, por vezes de formas relacionadas. Novas formas de influência política estão sendo habilitadas e alguns atores e agências locais estão sendo marginalizados, desprivilegiados ou burlados. (BALL, 2014, p. 181, grifos do autor).
}

Diante desse contexto, o avanço das pesquisas em políticas educacionais passa pela disposição dos pesquisadores em "[...] fazer perguntas diferentes e também procurar em lugares diferentes por respostas a essas perguntas" (BALL, 2014, p. 221). Talvez com isso seja possível observar o quão limitado (temporal e espacialmente) tem sido o conhecimento que até agora produzimos acerca dos "negócios" em educação e dos modos como os mercados têm influenciado o desenvolvimento das políticas educacionais de países como o Brasil. E, mais do que isso, talvez nos seja possível construir novas habilidades de investigação para pensar-se os cenários da educação no contemporâneo. Eis grande parte da potência do livro (e das ideias) de Stephen J. Ball (2014).

\section{Referência}

MAINARDES, J. Entrevista com o Professor Stephen J. Ball. Revista Olh@ares, Guarulhos, v. 3, n. 2, p. 161-171, jul./dez. 2015.

Práxis Educativa, Ponta Grossa, p. 850-854, v. 11, n. 3, set./dez. 2016 Disponível em: <http://www.revistas2.uepg.br/index.php/praxiseducativa $>$ 